\title{
Roland Brake and Ulrich Deller (eds): Community Development-A European Challenge
}

\section{Barbara Budrich, Opladen and Farmington Hills, 2008, 320 pp., \$28.90}

\author{
Sylvia I. Bergh \\ Published online: 19 August 2010 \\ (C) The Author(s) 2010. This article is published with open access at Springerlink.com
}

This edited volume contains more than 20 chapters of varying lengths on the topic of community development in various European countries (and one chapter from an American perspective). All contributions emerged from the EU-funded project 'Community Care Approach: A Strategy for Social Inclusion', running from around 2005 to 2008. The various chapters aim to deal with issues such as the relevance of community development approaches for the working practices of social work, how socio-economic projects are developed and implemented, assessing the experiences in the different countries and considering their applicability for other countries, and last but not least, the (negative) influence of politics on community work. The introductory chapter by the editors identifies the 'tension between the official support [funding] on the one hand and the autonomous community development actions that are sometimes directed against the authorities on the other' (Brake and Deller, 11) as running through the whole book.

The chapters are divided into four categories/parts: (a) information about community development in a specific European country (Belgium, Bulgaria, Germany, Hungary, Lithuania, Rumania and Spain); (b) definitions and methodologies of community development; (c) examples that could serve as best practices; and (d) theories and concepts.

According to the editors, the communalities and differences that emerge from the various country studies portray 'a lively image of the ways in which exclusion can be prevented by means of community development' (Brake and Deller, 15). This claim is difficult to back up, however, as the chapters do not present rigorous quantitative or qualitative evaluation studies (except for the chapters by Povilūnas on Lithuania, Lennartz and Deller on a youth bus project in Germany, and Aristu and Pasamar on Spain). Rather, for the most part, the case studies focus on the

Book review editor: Silvia Ferreira.

\section{S. I. Bergh $(\bowtie)$}

International Institute of Social Studies, Erasmus University Rotterdam,

The Hague, The Netherlands

e-mail: bergh@iss.nl 
potential positive impacts derived from the theoretical assumptions in the literature, probably because the projects were not advanced enough at the time of writing to observe measurable outcomes. Another area that could have been addressed in more depth is the role of politics and leadership in community development. Some contributions mention these issues in passing, but they are not theorized much, apart from a short mention in the chapter by Aristu and Pasamar who point out that 'Community Work through empowerment at once complements and opposes the [sic] representative democracy' (p. 91). Mostly, the case studies consist of depoliticized accounts of how various community development methodologies were applied.

The major shortcoming of the book is that it lacks explicit linkages between the various chapters, leaving the reader wondering how these cases can or should be compared (given also the influence of the political histories of some countries). The large number of theories, concepts, approaches and definitions as well as the many bullet-pointed lists of 'best principles' and standards for community development (which are only rarely assessed against concrete case studies), contribute to the impression that no serious effort was made among the project partners to develop common definitions and terminology, to question prevailing assumptions and to critically assess the experiences according to a common comparative framework.

Similarly, a concluding chapter that could have woven all the findings together, and return to assess the real extent of the tension identified at the beginning, is missing. The fact that several chapters have already been published elsewhere (or are reproduced in summarized form) also detracts from the value of this volume. Some of the chapters would have benefited from English language editing and shortening. Nevertheless, several chapters do stand out in that they concisely explain the history and context of social work in the Communist era (e.g. the chapters by Zafirov and Dinchiyska on Bulgaria, Vercseg on Hungary) and their consequences for the present situation.

In terms of the audience, the editors describe this book as a 'textbook for students of community development' (Brake and Deller, 12). However, given the conceptual and editorial shortcomings just mentioned, I would rather see its main audience as community development practitioners and funding agencies (such as the EU) that seek practical guidance as well as an understanding of the historical confluences that can explain the current national policy and legal frameworks for community development in the various (new EU-member) states.

Open Access This article is distributed under the terms of the Creative Commons Attribution Noncommercial License which permits any noncommercial use, distribution, and reproduction in any medium, provided the original author(s) and source are credited. 